\title{
RESEARCH PAPER \\ CHALLENGES WITH REFERENCE CITATIONS AMONG POSTGRADUATE STUDENTS AT THE KWAME NKRUMAH UNIVERSITY OF SCIENCE AND TECHNOLOGY, KUMASI, GHANA
}

\author{
R. B. Lamptey and H. Atta-Obeng \\ University Library, KNUST, Kumasi \\ E-mail: phanerosis75@yahoo.com and hagatta2010@yahoo.com
}

\begin{abstract}
Referencing or citing sources a writer uses is an important part of academic writing. It allows the writer to acknowledge the ideas or words of others used in his/her work and avoid plagiarism. Referencing also demonstrates that the writer has read relevant background literature and can provide authority for statements made. Proper citation allows others to locate the materials used. The researchers' experience while working on the Kwame Nkrumah University of Science and Technology (KNUST) Institutional Repository brought to the fore challenges postgraduate students encounter in citing references in their academic work. These include poor citing of reference works, inconsistencies in reference citation, use of different citation styles in theses submitted to the repository from the same department among others. Questionnaires and interview methods were employed. Five hundred and six questionnaires were distributed representing ten percent of the total population of postgraduate students of KNUST. Information sought in the questionnaire included students' biographical data, mode of assessment, departmental referencing format, knowledge of reference style formats, students' confidence in citing references and faculty's perception about the way students cited references. This paper seeks to identify and discuss some of the challenges KNUST postgraduate students face in their academic writing. The study found out that KNUST postgraduate students have problems in mastering reference style formats because of the variations in citation. Students tend to rely on books, lecturers or librarians for assistance in ensuring the accuracy of citations they use in their work. Students were not able to identify the citation format they used; they could not cite references for books and journal articles with confidence. Among the recommendations made were that, librarians should play a wider role in the arena of academic integrity, faculty and librarians should collaborate in teaching students about reference citation formats used in academia. College librarians should advocate for the standardization on reference styles in their various colleges. Library orientation given by librarians should be replaced with Information Literacy skills to be offered to students in the first and final years.
\end{abstract}

Keywords: Documentation Styles, Citation, Bibliographic, KNUST 


\section{INTRODUCTION}

In academic writing such as assignments, theses, research articles and reports, it is the standard practice to give an overview of the current knowledge about a topic and to provide evidence to support the points that one makes. These ideas will form the foundation for one's own arguments and will be integrated into one's own work by:

- $\quad$ quoting (using the exact words of another);

- paraphrasing (using the ideas of another in your own words);

- summarising (using the main points of another); and

- translating the original text and summarising or paraphrasing it. (UEfAP)

Acknowledging other people's ideas or opinions in one's work is a feature of academic work. This type of acknowledgement is variously known as referencing, documentation, or reference citations. Although their origin is obscure, modern reference style formats are associated with the information explosion of the 1980's and 90's that witnessed a rapid increase in scholarly publications, compelling writers and publishers to find convenient methods to reference the different sources they consulted in their publications (Krumnel, 2002). These referencing methods are used in different fields and for specific purposes. Among the varied formats and styles that are in current use are Vancouver, Harvard, American Psychological Association (APA), Modern Language Association (MLA), American Sociological Association (ASA), Council of Science Editors (CSE) and Turabian (often referred to as Chicago). Turabian has two versions, namely, Chicago/Turabian Notes which is often used by History and Humanity disciplines and Chicago/ Turabian Author-Date often used for the Physical, Natural and Social Sciences. All of these styles have the following features: author's name with surname written first, followed by the other name(s) and/or initials of the author, title of publication, edition statement (if any), and imprint.
For an article in a journal publication, the following common features are found in all the reference style formats: author's surname followed by other names or initials, date (that is the year in which the journal was published), title of the article, title of journal, volume and part number (if any), and page number(s) of the article in the journal. For an article from an electronic source, the following common features are found in all the reference style formats: author(s), year, title of document (type of medium, example email, blog), organisation responsible (optional). Available at: web site address /Uniform Resource Locator (URL), [date article was accessed].

Citing references is essential in academia. It gives credit where it is due, adds authority to a statement and shows that a writer is not just giving his/her views but also including those of other writers. It also illustrates a point or offers support for an argument a writer wants to make, and enables readers of a work to find the source material (Damarell et al., 2005). References need to be cited where documents are referred to in the text or a work. Accuracy and consistency are essential to enable readers to identify and locate the materials referred to (Flinders University, 2002).

Kwame Nkrumah University of Science and Technology (KNUST) has an online digital repository (KNUSTSpace) which holds the research output of the members of the university. The collection include thesis received from postgraduate students within the six Colleges (College of Art and Social Sciences, College of Architecture and Planning, College of Health Science, College of Science and the College of Agriculture and Natural Resources) consisting of different departments and faculties. The researchers identified some errors in reference citations in postgraduate students' academic work while working on the KNUSTSpace. These included poor citing of reference works, inconsistency in reference citations and use of different citation styles in theses submitted to the same Department. Other 
errors detected were works cited in text that were not included in the references at the end of the thesis and works not cited in text that were included in the references. This is a case study at KNUST and it is focused on the challenges postgraduate students face in reference citation.

\section{Research questions:}

This paper will therefore provide an overview of current referencing practices in KNUST and what faculty and librarians can do to help students learn to use the varied citation style formats. In particular, the study is aimed at disseminating and drawing attention to the need for standardising of reference style formats across colleges within KNUST. The study therefore seeks answers to the following questions:

1. What is the status of reference citation with regard to academic writing and publishing at KNUST?

2. What are the departmental requirements for references in students' academic papers?

3. Which reference citations do students frequently use in writing papers at KNUST?

4. What challenges do students have in citation?

5. What is faculty's perception about the way students cite references in their academic papers?

The study is significant because not much has been written on reference citation and its importance and therefore, a lot of awareness needs to be created. Again much of the literature on citation are written within the citation analysis.

\section{LITERATURE REVIEW}

When submitting written work, it is essential for any source used in its preparation to be accurately cited. A clear and consistent style is needed to ensure that those reading your work can find the source you have quoted to follow up your arguments, or to verify quotations.

Citations make one's writing more persuasive, they are not used simply to avoid plagiarism; they have other important roles as well. By citing the work of a particular author you acknowledge and respect the intellectual property rights of that researcher. Researchers are free to use millions of ideas, insights and arguments published by other writers.

According to Hart (2005) your citations map the space of your discipline, and allow you to navigate your way through your chosen field of study. In academic communities, the ethics of research demand that writers be credited for their work and their writing. Not to do so is to plagiarize, to intentionally or unintentionally appropriate the ideas, language, or work of another without sufficient acknowledgment.

Neville (2007) defines referencing as the process of acknowledging one's sources. Sources may include anything you take information from: example books, journals, magazines, newspapers, websites, lecture notes, legislation, maps, television and radio programmes, work of art and dramatic performances. Failure to reference correctly or worse still not to reference at all may lead to accusations of plagiarism. Plagiarism is a serious offence in the academic community and may lead to disciplinary action.

According to Bowden and Di Benedetto (2001) citing references is an art or skill which requires acknowledgement. They recommend that there should be collaboration between Faculty and Librarians in teaching students about reference citation formats used in academia.

They further attest that collaboration between faculty and librarians is beneficial because many sources of information especially those available in electronic format may not necessarily be authoritative or accurate and therefore by collaborating with librarians, faculty would be able to help students evaluate their sources of information and cite references appropriately.

Kendall (2005) did a study in which students' 
citing behavior was found to be rife with errors, even after in-class citing instruction; a tutorial was created to address common errors and students completed the tutorial during the following academic year; the same students were pretested before completing the tutorial and posttested after completing the tutorial, with the results showing improvement in some areas of student citation performance.

A search of Library, Information Science \& Technology Abstracts for librarians and diagnosing and plagiarism retrieves articles that assume librarians perform the role of assisting faculty in locating students' sources of plagiarism (Nimsakont, 2008; Mandray, 2008). However, the authors call for a wider role for librarians in the arena of academic integrity. They advocate that librarians should be partners in campus-wide initiatives that teach students the tenets of academic honesty.

According to De Voss and Rosati (2002) issues of plagiarism are complex, and made all the more complicated by students' increasing use of the world wide web (WWW) as a research space. In their view, the use of the virtual space of the web and the downloading and cutting and - pasting techniques available pose new challenges related to the issues of plagiarism.

They contended that two fold approaches to avoiding plagiarism are;

(a) Engaging students in discussions of plagiarism.

(b) Designing assignments that deter students from plagiarizing.

Harris (2004) asserts that, the availability of textual material in electronic format has made plagiarism easier than ever. Copying and pasting of paragraphs or even entire essays can now be performed with just a few mouse clicks. He identified major causes of students' inability to cite sources properly as follows;

(1) Students are natural economizers who are interested in the short test course and in so doing do not bother to learn how to cite sources properly.

(2) They are faced with too many choices so that they put off low priorities.

(3) They have poor time management and planning skills and thus do not understand the hours required to develop a good research paper.

(4) Some fear that their writing ability is inadequate and would want to look for a superior product to make it as their own creation.

Kendall (2005) argues that many students experience difficulties with citing and referencing bibliographic sources. Newton (1995) states that the common challenge students face in citing is reliance on inappropriate source for instruction on how to reference. In her research work, almost half of the students she interviewed acknowledged that they knew they were probably not doing it right, but instead of consulting their tutor on the required reference text in the course, or the course handouts, they turned to unsuitable sources for help; friends, parents or old handout from high school. In these cases, the advice they got or remembered was often misleading.

In another study, Clarke and Oppenheim (2006) examined 310 references in student papers and found that 24.9 percent contained citation errors. Of the works cited lists, 80 percent contained at least one error. They found that while students felt secure citing print-based materials, " 56.9 percent of students surveyed did not feel confident when referencing electronic journals. The younger students were found to feel more confident when citing electronic formats. However, their perceived ability to cite does not necessarily match their levels of competence. Several students commented on the difficulties of citing electronic materials. Students suggested that their references might improve with more instruction, repeating the instruction at multiple times for part-time students, and returning corrected reference lists during the edit- 
Park (2010) is of the view that one solution to this challenge, is to integrate key components of proper referencing skills in a course assignment, letting students know they will lose marks or grades if they do not cite properly. This will deter them from plagiarizing. He further argues that, some students may require additional impetus that comes from one-onone instruction or written assignments.

Mounce (2010) suggested that librarians in academic institutions should consider teaching research skills to the university students to solve this problem of improper citation. Kendall (2005) is of the view that students use of the online tutorial on citing and referencing has an impact on students' learning experiences in improving students' referencing skills.

\section{METHODOLOGY}

Data collection instruments employed in gathering information and data for the study included questionnaire for students and interviews with the college Provosts. A 16-item questionnaire was designed, pre- tested on few selected students and reviewed by professional colleagues at the KNUST Main Library to ensure validity. Information sought in the questionnaire included students' biographical data, mode of assessment, departmental referencing format, knowledge of reference style formats, confidence in citing references, and faculty's perception about the way students cite references. Both open and close-ended questions were used to enable respondents express their opinion freely.

Due to logistical constraints, the purposive sampling method was used to select 506 of the 5,060 postgraduate students in the six colleges representing $10 \%$ of the various postgraduate programmes in the University. The colleges were classified into six clusters, and each college was given a $10 \%$ quota to ensure uniformity. Respondents were asked to fill the questionaire and return them immediately.

Data was collected between October and Dec- ember 2010. All 506 completed copies of the questionnaires $(100 \%)$ were returned in usable format. Provosts of three colleges were also at post to be interviewed by the researchers at the time of collecting the data.

Data was analyzed using the Statistical Package for the Social Sciences (SPSS) and computed as tables and graphs of the responses. The biographical data of the respondents in the questionnaire were not analysed because they were only intended to gather that information to enable the researchers to know the spread of the people interviewed. The responses from the face to face interview conducted with the provost of the three colleges (College of Arts and Social Sciences, College of Agriculture and Natural Resources and the College of Architecture and Planning) were analysed qualitatively.

Table one shows the composition of responses from the six Colleges at KNUST.

\section{Findings}

Citing references was assumed by the authors to be a topic that is taught as part of the Research Methods course in the various departments, and therefore students were required to adopt the format of their respective Colleges or Departments. The survey however, revealed the contrary.

\section{Status of Reference Citation and Academic} Writing / Publishing in KNUST

Research activities are a major component in university education. At KNUST, the end of semester papers, written assignments, project works, theses and seminars form part of students' mode of assessment. These involve sources consulted in writing an academic or a research work. Incorrect citation reflects in graduate students' theses and dissertations, some of which are sometimes returned to them by their supervisors to correct before resubmission for the award of a post-graduate qualification. However, KNUST School of Graduate Studies manual for the thesis presentation for Masters and Doctoral degrees (2010) makes 
Table 1: Distribution of respondents from the six colleges

\begin{tabular}{lrr}
\hline \multicolumn{1}{c}{ COLLEGE } & POPULATION & $\begin{array}{c}\text { SAMPLE SIZE } \\
(\mathbf{1 0 \%} \text { of Population) }\end{array}$ \\
\hline Architecture and Planning & 330 & 33 \\
Arts and Social Science & 1530 & 153 \\
Engineering & 180 & 18 \\
Sciences & 2490 & 249 \\
Health Science & 320 & 32 \\
Agricultural and Natural Resources & 210 & 21 \\
TOTAL & $\mathbf{5 0 6 0}$ & $\mathbf{5 0 6}$ \\
\hline
\end{tabular}

Source: Field survey (2010)

provision for the use of two major styles. These MLA and APA (for Humanities styles), and Chicago/Turabian and the Council for Science Editors CSE (for Scientific styles) manuals. (Best Free Style Guide Resources for MLA, APA, Chicago, and CSE, 2012)

\section{Departmental Referencing format}

In all, (481) $95 \%$ of the respondents indicated that citing references in a departmental style is a requirement but are not sure of the exact format to use, whereas only (25) $5 \%$ indicated that they did not know if there was any special departmental citation style. On the other hand (378) $74.7 \%$ indicated that they frequently use bibliography, (101) $20 \%$ use footnotes, and (27) $5.3 \%$ indicated that they used other methods. Also (397) $78.5 \%$ indicated that they acquired their knowledge of citing references in the University, whereas (68) $13.5 \%$ indicated that they learned how to cite references from their lecturers. A minority (10) $2.07 \%$ of the respondents stated that they learned about citing references from colleagues, (18) $3.5 \%$ indicated that they learned how to cite references from books and journals.

There is widespread recognition on the importance of providing reference citations in academic work among KNUST postgraduate students and this finding is corroborated by Park (2010) who suggested that, one solution to this challenge, is to integrate key components of proper referencing skills in a course assignment, letting students know they will lose marks or grades if they do not cite properly.

\section{Knowledge of Reference Formats}

Reference format samples from books and periodicals were given to respondents for them to indicate the different citation styles and those they frequently used. This was to comprehend the challenges postgraduate students at KNUST experienced. This question brought serious discrepancies among respondents, with (455) $90 \%$ stating that they used more than one referencing style while (51) $10 \%$ indicated that they did not know the technical names of the format they used.

\section{Sample Citations}

The following sample citations were given to respondents for them to indicate those they were familiar with. The citation styles (in bold) were omitted from the specimen given to respondents.

\section{Sample Citations for Books and Journals Turabian $7^{\text {th }}$ Edition \\ Book}

Guy Cowlishaw and Robin Dunbar, Primate Conservation Biology (Chicago: University of Chicago Press, 2000), 104-7. 
Journal

Smith, John Maynard. "The Origin of Altruism." Nature 393 (1998): 639-40.

\section{Harvard Style}

Book

Weiss, T. D. and Coatie, J. J., 2010. The World Health Organisation, its history and impact. London: Perseus.

Journal

Boughton, J. M., 2002. The Bretton Woods proposal: a brief look. Political Science Quarterly, 42(6), pp.564-572

\section{APA $6^{\text {th }}$ Edition \\ Book}

Calfee, R. C., and Valencia, R. R. (1991). APA guide to preparing manuscripts for journal publication. Washington, DC: American Psychological Association.

\section{Journal}

Wegener, D. T., and Petty, R. E. (1994). Mood management across effective states: The hedonic contingency hypothesis. Journal of Personality \& Social Psychology, 66, 1034-1048.

\section{MLA $7^{\text {th }}$ Edition}

Book

Gillespie, Paula, and Neal Lerner. The Allyn and Bacon Guide to Peer Tutoring. Boston: Allyn, 2000.

\section{Journal}

Buchman, Dana. "A Speci`al Education." Good Housekeeping Mar. 2006: 143-48.

\section{Council of Science Editors (CSE) \\ Book}

McCormac J. S, and Kennedy G. 2004. Birds of Ohio. Auburn (WA): Lone Pine, p. 77-78.

Journal

Meise C. J, Johnson D. L, Stehlik L. L, Manderson J, and Shaheen P. 2003. Growth rates of juvenile Winter Flounder under varying environmental conditions. Trans Am Fish Soc
132 (2):225-345.

\section{American Sociological Association (ASA) \\ Book}

Mason, Karen. 1974. Women's Labor Force Participation. Research Triangle Park, NC: National Institutes of Health

\section{Journal}

Scholarly journal: Conger, Rand. 1997. "The Effects of Positive Feedback on Direction and Amount of Verbalization in a Social Setting." American Journal of Sociology 79: 1179-259.

\section{Standard Referencing Format}

Fig. 1 shows responses when respondents were asked to indicate if there is a standard referencing format used in their various departments. In all (206) $40.7 \%$ of the respondents said there was, (156) $30.83 \%$ indicated that there was not, and (144) $28.45 \%$ said they did not know. This tends to indicate that not all the Colleges have a standard referencing format. This situation therefore needs urgent attention.

The concern of the majority of the students was that they did not do it right as expected. One respondent remarked;

"As far as this issue is concerned, much has to be done, we are only told to go to the library, and search for a particular book, the author is A or B and take down details. Most of us are sometimes left in limbo; sometimes we end up changing the format of the few students who are fortunate to have access to these materials and then we present them so as to prevent us facing the penalty".

Other respondents (304) $60 \%$ observed that every College should at least have a guide to the style of referencing which students should use to enhance the understanding of students in that direction for it is embarrassing for 'us' as students to lack such knowledge. This research confirms with that of Kendall (2005) who argues that, many students experience difficulties with citing and referencing bibliographic 
sources where in his study, students' citing behavior was found to be rife with errors.

Fig. 2 sought answers to a question pertaining to knowledge about the most used referencing style. It was deduced that (172) $34 \%$ of respondents did not know the technical name for the referencing format being used, (141) $28 \%$ ind- cated Harvard, (120) 24\% American Psychological Association, (42) 8\% Modern Language Association, (16) $3 \%$ Council of Science Editors. Eight of the respondents did not answer that question. The high response rate for those who did not know was an indication that postgraduate students faced some challenges in reference citation at KNUST.

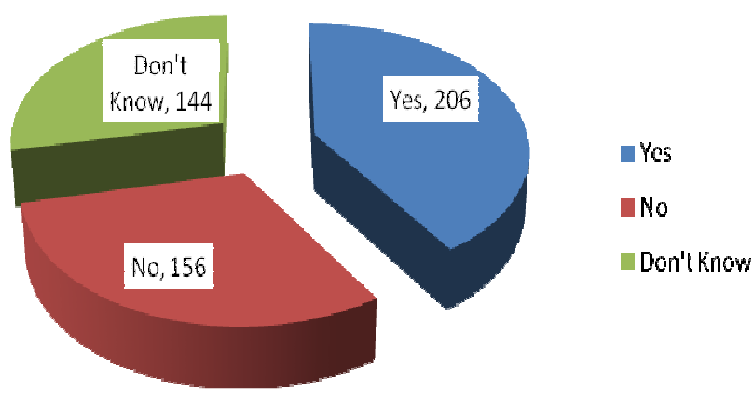

Fig. 1: Standard style/ format in the Departments/Colleges

Source: Field survey (2010)

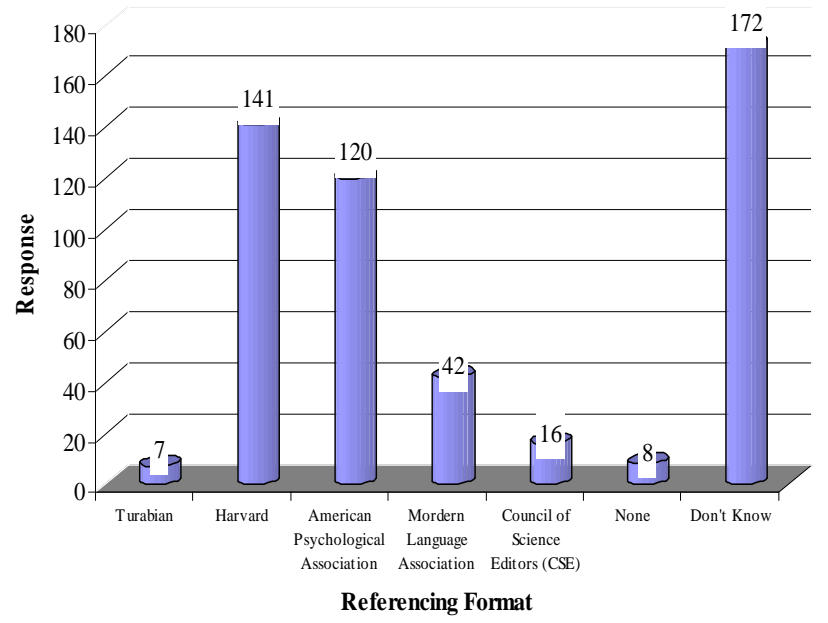

Fig. 2 : Reference style formats

Source: Field survey (2010) 


\section{Challenges in Referencing}

Students frequently ask questions at the Electronic Resources Department in the Main Library of KNUST about how to cite references and seem confused over citation formats for books and journals. It was deduced from the questionnaire that students lack the confidence in properly citing references and seek assistance from their colleagues and librarians. Students are under the mistaken impression that the only motive behind citing references is to avoid plagiarism and to earn good marks. Others remarked that citing references is only a requirement to show the titles of sources consulted in writing their papers.

Such remarks reveal the difficulties postgraduate students face in properly citing references in their theses. It is evident that some postgraduate students lack confidence in identifying the names of the citation styles used in the department and they even get confused about which citation style to adopt. Their confusion becomes more complicated when faculty do not recommend any specified style or format. They also show that postgraduate students are not taught how to cite references and they adopt whatever citation style they are referred to by lecturers, librarians or colleagues. This has resulted in different citation styles being used in their theses. This therefore means that students should be taught why referencing is important as well as the acceptable format used in the various colleges and departments.

\section{Confidence in Referencing}

Students' responses to the questionnaire on confidence in referencing revealed that, they were not confident in using the different reference styles or formats to authenticate their work. A minority of (205) $37.9 \%$ indicated that they were confident in referencing, whereas (301) $62.1 \%$ indicated that they were not confident. The $37.9 \%$ that indicated being confident were asked to identify the citation format for books and journal articles in the sample citation given to them. It is significant to note that they could not identify the formats.
Respondents were also asked to write down the citation formats they are confident with. Most of them (239) $65 \%$, wrote the title of the publication followed by the year of publication and then the author. Others wrote the reverse with no distinction made for authored and edited works. This research agrees with Clarke and Oppenheim (2006) in their work where $80 \%$ of references in student papers contained citation errors.

These errors are probably indications of the lack of agreement over the confidence and consistent use of reference style formats in the Colleges at KNUST. They also illustrate the students' lack of awareness of the different citation or referencing styles which they used in documenting their academic work.

\section{Faculty's Perception}

The responses from the face-to-face interview conducted with the provost of the three colleges (College of Arts and Social Sciences, College of Agriculture and Natural Resources and the College of Architecture and Planning) regarding the topic indicated that although, there is a standard format for the Graduate School, lecturers often leave the students to use formats lecturers are familiar with.

Students were also required from the questionnaire to indicate their perception of how faculty rated the way students cited references in their academic work. The general rating ranged from "poor, satisfactory, good, very good" with emphasis on "citing with accuracy and standardized form" or "the way students like it". Such ratings imply that faculty were not too keen to know the formats students used in documenting their work. It could be assumed by the researchers that faculty either took for granted that students knew how to properly cite or that faculty might be of the opinion that it was the responsibility of students to know how to cite correctly without even being taught. The researchers' observation with some faculty members were that, they asked students to use the citation format which they the supervisor or 
lecturers were familiar with. Interviews with the three College Provosts who were available indicated that, the KNUST Graduate School had standard referencing format which students are to use, but somehow students end up writing their theses using the citation format which the supervisors' accept so far as it is consistent. They all acknowledge the fact that something need to be done for students to conform to the required referencing format. Our findings revealed that there was no uniformity in citation styles within the Colleges.

The nature of the problem became even more glaring when some respondents indicated that faculty did not recommend any specific format or style but left the students to use any format they were comfortable with as long as as long as they maintained consistency. One respondent observed that "every college should at least have a sample reference format displayed to enhance the understanding of students in that direction as it embarrasses students".

\section{THE WAY FORWARD}

The study revealed that students had challenges mastering reference style formats in view of the variations in citation and this cuts across in the Colleges at KNUST. Students tend to rely on books, their friends and librarians for assistance in ensuring the accuracy of citations they use in their work. Students were not able to identify the citation formats they used. KNUST postgraduate students could also not cite references for books and journal articles with confidence. The ability to relate one's work to existing knowledge in the field is a skill that needs to be mastered by every student, and should therefore be taught by faculty and librarians to the first and final year undergraduate and postgraduate students of KNUST.

It is therefore recommended that, library orientation given by librarians to new students at the beginning of every academic year should be replaced with User Education or Information Literacy module to be offered by students in the first and final years. This view is also shared by
Mounce (2010), who suggested that, librarians in academic institutions should consider teaching research skills to the university students to solve this problem of improper citation. Librarians in collaboration with Faculty should prepare citation style guides to be used by postgraduate students for the various Colleges or Departments. Students should be given the acceptable format used in their respective departments and Colleges. There is the need to organise workshops for postgraduate students during their second year on how to cite references. The resource persons should include librarians and academic staff who are prolific in writing and therefore know the correct way for citing references. To end, college Librarians should advocate for a standardized set of reference styles in their various Colleges by organizing workshops for Faculty and students.

\section{CONCLUSION}

The ability to pay attention to detail and follow instructions accurately should be particularly important for all students. The emphasis given to referencing practice at an early stage in their studies will be of wider benefit. It is hoped that Librarians at KNUST Library, by exploring the findings of the studies listed previously, will glean ideas which they can use to help improve KNUST students' abilities to use the standard citations format through the enhancement of the current library instruction.

\section{REFERENCES}

American Psychological Association (2010). $6^{\text {th }}$ Edition. Available at http:// owl.english.purdue.edu/owl/resource/560/08/ (Accessed on 28/10 2010)

American Sociological Association (2010). Available at http://markfoster.org/asa.html (Accessed on 28/10 2010)

Best Free Style Guide Resources for MLA, APA, Chicago, and CSE (2010). Available at http://www.bestfreeonline.net/resources/mlaapa-chicago-cse/ (Accessed on 30/12/2012) 
Reference citations among postgraduate students...

Bowden, T. S. and DiBenedet, A. (2001). "Information literacy in a biology laboratory session: an example of librarian-faculty collaboration". Research Strategies 18: 143149

Clarke, M. E. and Oppenheim, C. (2006). "Citation behaviour of information science students II: postgraduate students". Education and Information, $24: 1-30$

Council of Science Editors Style Guide (2010). Available at http://library.osu.edu/help/ research-strategies/cite-references/cse/csestyle-guide-articles/ (Accessed on 28/10 2011)

Damarell, R., Badcock, J. and Miller, R. (2005). Author-date (Harvard) referencing guide, $3^{\text {rd }}$ ed. Adelaide: Flinders University, School of Nursing and Midwifery.

De Voss, D. and Rosati, A. (2002). 'It wasn't me, was it? Plagiarism and the web', Computer and Composition, 19 (2):191- 203.

Flinders University (2002). Style manuals for authors, editors and primaries, $6^{\text {th }}$ ed. Canbera: Smooks and Company.

Hart, C. (2005). Doing Your Masters Dissertation: Realizing Your Potential as a Social Scientist. Available at: http:// books.google.com.gh/books? hl=en\&lr=\&id=drmwc95ezaYC\&oi=fnd\&pg $=$ PR7\&dq $=$ Your + citations + map + the + space + of+your+discipline\&ots=TRnLBvY1aq\&sig $=\mathrm{Y} \mathrm{A} \mathrm{q} \mathrm{L} 6$ A p T L V U 7 V q $9 \mathrm{~m}$ N2q2uLnF5Y\&redir esc $=y \# v=$ onepage \& $\mathrm{q} \&$ $\underline{\mathrm{f}=\text { false }(\text { Accessed on 10/02/12) }}$

Harris, R. (2004). Anti-Plagiarism Strategies for Research Papers. Available at http:// www.virtualsalt.com/antiplag.htm (Accessed on 8/06 2012)

Harvard System of Referencing Guide (2010). Available at http://libweb.anglia.ac.uk/refere- ncing/harvard.htm (Accessed on 28/10 2010)

Kendall, M. (2005). Tackling student referencing errors through an online tutorial. Aslib Proceedings: New Information Perspectives 57(2):131-145. Available at www.emeraldinsight.com/0001-253X.htm (Accessed on 10/10/2012)

KNUST School of Graduate Studies (2010). Manual for thesis presentation for masters and doctoral degrees, Kumasi: KNUST, 116

KNUST (2008). Vice-Chancellor's Report $200842^{\text {nd }}$ Congregation. Kumasi- Ghana: KNUST, 359

Krumnel, D. W. (2002). Bibliography. In Encyclopedia of communication and information, vol. 1 (ACA-FUN), ed. Jorge Reine Schement, 75-76. New York: Macmillan.

Mandray, A. (2008). "The anatomy of a plagiarism initiative: one library's campus collaboration”, Public Services Quarterly 4(2): $111-25$

Modern Language Association (2010). $7^{\text {th }}$ Edition. Available at http:// ow l.english.purdue.edu/ow l/ resource/747/06/ (Accessed on 28/10 2010)

Mounce, M. (2010). "Working together: Academic Librarians and faculty collaboration to improve students' information literacy skills: a literature review 2000-2009". The Reference Librarian, 51(4):300-320

Newton, J. (1995). Plagiarism and the Challenge of Essay Writing: Learning from our Students. A paper presented at the Annual Conference of the American Association of Higher Education, Boston, MA. Available at http://facstaff.elon.edu/sullivan/ cheatpap.htm (Accessed on 10/02/12) 
Neville, C. (2007). The Complete Guide to Referencing and Avoiding Plagiarism.

Available at http://books.google.com.gh/ b o o k s ? h $1=$ e n \& $1 \mathrm{r}=\&$ i d $=\mathrm{T}-$ JAVVKLjTAC\&oi=fnd\&pg=PP1\&dq=refer encing+is+the+process+of+acknowledging + your + sources\&ots=h0aturYz7f\&sig=rYvZ 7x7bzPScmABeWon_A84qFXs\&redir_esc= $\mathrm{y} \# \mathrm{v}=$ onepage \& $\mathrm{q}=$ referencing $\% 20$ is $\%$ $20 \mathrm{the} \% 20 \mathrm{process} \% 20$ of $\%$ 20 acknowledging $\% 20$ your $\%$ 20sources\&f=false (Accessed on 10/02/12)

Nimsakont, E. (2008). "How can academic librarians educate students about plagiarism?", PLNA Quarterly, 72 (3):10-12

Park, C. (2010). In Other (People's) Words: Plagiarism by university students literature and lessons, Assessment \& Evaluation in
Higher Education. 28(5), 471-488

Park, S., Lori A. Mardis and Connie Jo Ury (2010). I've lost my identity - oh, there it is . . . in a style manual Teaching citation styles and academic honesty Reference Services Review 39(1):42-57. Available at www.emeraldinsight.com/0090-7324.htm (Accessed on 10/10/2012)

Turabian, K. L. A. Manual for Writers of Research Papers, Theses, and Dissertations. Available at http://press.uchicago.edu/ books/turabian/turabian_citationguide.html (Accessed on 28/10 2010)

UEfAP, (2010) Academic writing: features of academic writing (2010). http:// www.uefap.com/writing/feature/ featfram.htm (Accessed on 20/04/2010) 